\title{
Correction to: The effects of virtual human gesture frequency and reduced video speed on satisfaction and learning outcomes
}

\section{Robert O. Davis ${ }^{1}$ (D) $\cdot$ Li Li Wan $^{2} \cdot$ Joseph Vincent ${ }^{3} \cdot$ Yong Jik Lee $^{4}$}

Published online: 12 July 2021

(c) Association for Educational Communications and Technology 2021

\section{Correction to: Education Tech Research Dev https://doi.org/10.1007/s11423-021-10010-x}

The original publication inadvertently referenced agent persona instead of satisfaction in the title and abstract (lines 11 and 17). The abstract misstated the use of structural equation modeling as the method of analysis.

The original article has been corrected.

Publisher's Note Springer Nature remains neutral with regard to jurisdictional claims in published maps and institutional affiliations.

The original article can be found online at https://doi.org/10.1007/s11423-021-10010-x.

Robert O. Davis

red1020@gmail.com

1 Department of English Linguistics and Language Technology, Hankuk University of Foreign Studies, 107 Imun-ro, Imun-dong, Dongdaemun-gu, Seoul, South Korea

2 Business School, Information System and Operation Management, Hankuk University of Foreign Studies, 107 Imun-ro, Imun-dong, Dongdaemun-gu, Seoul, South Korea

3 English for International Conferences and Communication, Hankuk University of Foreign Studies, 107 Imun-ro, Imun-dong, Dongdaemun-gu, Seoul, South Korea

4 General Education Department, Woosuk University, 443, Samnye-ro, Wanju-Gun, Jeon-Ju City, Jeollabuk-do 55338, South Korea 